\title{
Antioxidant and tyrosinase inhibition activity of the fertile fronds and rhizomes of three different Drynaria species
}

\author{
Joash Ban Lee Tan ${ }^{*}$ and Yau Yan Lim
}

\begin{abstract}
Background: For generations, the rhizomes of Drynaria ferns have been used as traditional medicine in Asia. Despite this, the bioactivities of Drynaria rhizomes and leaves have rarely been studied scientifically.

Methods: This study evaluates the antioxidant properties of the methanolic extracts of the fertile fronds and rhizomes from three species in this genus: Drynaria quercifolia, Drynaria rigidula and Drynaria sparsisora. The phenolic and flavonoid contents of the samples were respectively quantified with the total phenolic content (TPC) and total flavonoid content (TFC) assays, while the antioxidant activities were determined via measuring the DPPH radical scavenging activity (FRS), ferric reducing power (FRP), ferrous ion chelating (FIC) activity and lipid peroxidation inhibition (LPI). The tyrosinase inhibition activity of all three species was also reported.
\end{abstract}

Results: The fertile fronds of D. quercifolia were found to exhibit the highest overall TPC (2939 \pm 469 mg GAE/100 g) and antioxidant activity amongst all the samples, and the fertile fronds of D. quercifolia and D. rigidula exhibited superior TPC and FRP compared to their rhizomes, despite only the latter being widely used in traditional medicine. The fronds of D. quercifolia had high tyrosinase inhibition activity (56.6 $\pm 5.0 \%$ ), but most of the Drynaria extracts showed unexpected tyrosinase enhancement instead, particularly for D. sparsisora's fronds.

Conclusion: The high bioactivity of the fertile fronds in the fern species indicate that there is value in further research on the fronds of ferns which are commonly used mostly, or only, for their rhizomes.

Keywords: Fern rhizome, Fertile fronds, Fern leaves, Free radical scavenging, Tyrosinase inhibition

\section{Background}

Interest in phenolic compounds has been on the rise due to their potential human health benefits [1]. They are the most abundant class of plant antioxidants-compounds capable of deactivating or stabilizing free radicals, thereby reducing free-radical-mediated cellular and tissue damage [2]. Plant antioxidants have been purported to have anti-aging properties, and may prevent numerous diseases such as cancer, diabetes, neurodegenerative diseases [3], atherosclerosis, and cardiovascular diseases [4]. Some phenolic compounds are also able to inhibit tyrosinase, an enzyme responsible in melanogenesis and

*Correspondence: joasht@hotmail.com

School of Science, Monash University Malaysia, Bandar Sunway, 46150 Petaling Jaya, Selangor, Malaysia enzymatic browning. This has considerable commercial value in the cosmetics industry as a skin-whitening agent, or an anti-browning agent in the food industry [5]. Tyrosinase inhibition has also been discovered to reduce the viability of catecholaminergic neuronal cells [6] which have been linked to several psychiatric and neurodegenerative disorders, thus providing a possible new treatment in the future [7].

The rhizomes of the Drynaria genus of ferns have a long history of being used as traditional medicine, particularly in India [8], China [9] and Southeast Asia [10]. Drynaria quercifolia (L.) J. Smith is one of the best-known members of this genus, commonly used in Ayurvedic medicine ("Ashwakatri") [8] where its boiled rhizome decoction is consumed orally for its anti-pyretic properties; and used as a treatment for tuberculosis 
[10], diarrhea, cholera, fever, typhoid, syphilis and skin diseases [11]. Additionally, the extract of this fern was capable of inhibiting wildtype and multidrug-resistant bacteria such as Neisseria gonorrhoeae and Streptococcus$\beta$-haemolyticus [10]. Due to the ethnobotanical value of the $D$. quercifolia's rhizomes, it has been the emphasis of phytochemical-centric research on the species. In comparison, little research has been conducted on the fertile fronds (leaves), which are sometimes used in conjunction with the rhizome to treat tuberculosis and throat infections [12], or as a poultice to reduce swelling [8].

The rhizomes of Drynaria rigidula (Sw.) Beddome and Drynaria sparsisora (Desv.) T. Moore have also been claimed to treat similar diseases as the rhizomes of $D$. quercifolia, such as diarrhea and gonorrhea [13]. However, unlike $D$. quercifolia, there have been no reports on the bioactivity of the fertile fronds of both species. $D$. rigidula is an endangered species in many locations [14], while $D$. sparsisora is nearly identical to $D$. quercifolia in physical appearance, but with shorter fertile fronds [15] and a dark-colored scaly rhizome [16]. This study represents the first time that the antioxidant activities of $D$. rigidula and $D$. sparsisora fertile fronds and rhizomes have ever been reported, and the comparison between the antioxidant activity of fertile fronds and rhizomes in a fern remains a rarely-explored avenue in most literature. This is also the first time that the tyrosinase inhibition activity for any of these species has ever been reported.

\section{Methods}

\section{Collection of fern samples}

The fertile fronds and rhizomes of D. quercifolia and $D$. rigidula were obtained from the Putrajaya Botanical Garden, Kuala Lumpur, while the leaves and rhizomes of $D$. sparsisora were obtained from Sunway, Petaling Jaya. The ferns were identified by plant taxonomist Anthonysamy S., formerly from University Putra Malaysia.

\section{Chemicals and reagents}

The various reagents used throughout this project were purchased from suppliers as follows. TPC analysis: Folin-Ciocalteu's phenol reagent $(2 \mathrm{~N}, \mathrm{R}$ and $\mathrm{M}$ Chemicals, Essex, UK), gallic acid (98 \%, Fluka, Steinheim, France), anhydrous sodium carbonate (99 \%, J. Kollin, UK); total flavonoid content (TFC) analysis: aluminium chloride (99.5\%, Bendosen Laboratory Chemicals, Bendosen, Norway), potassium acetate ( $99 \%, \mathrm{R}$ and $\mathrm{M}$ chemicals), quercetin ( $98 \%$, Sigma St. Louis, MO, USA); diphenyl-2-picrylhydrazyl (DPPH.) assay: 1,1-diphenyl2-picrylhydrazyl (90\%, Sigma, St. Louis, MO, USA); ferric reducing power (FRP) assay: ferric chloride hexahydrate (100\%, Fisher Scientific, Loughborough, UK), potassium ferricyanide ( $99 \%$, Unilab, Auburn, Australia), trichloroacetic acid (99.8 \%, HmbG Chemicals, Barcelona, Spain), potassium dihydrogen orthophosphate (99.5 \%, Fisher Scientific, Loughborough, UK), dipotassium hydrogen phosphate (99 \%, Merck, Darmstadt, Germany), iron chloride ( $99 \%$, R\&M Chemicals, Petaling Jaya, Malaysia); ferrous ion chelating (FIC) assay: ferrozine (98\%, Acros Organics, Morris Plains, NJ, USA), ferrous sulphate hepta-hydrate (HmbG Chemicals, Barcelona, Spain), ethylenediaminetetraacetic acid (EDTA) (98 \%, Sigma, St. Louis, MO, USA); lipid peroxidation inhibition (LPI): $\beta$-carotene (Sigma, St. Louis, MO, USA), chloroform (Fisher Scientific, 99.9 \%, Loughborough, UK), linoleic acid, $\mathrm{C}_{18} \mathrm{H}_{32} \mathrm{O}_{2}$ (Fluka, Steinheim, France), Tween 40 (Fluka, Steinheim, France); tyrosinase inhibition activity: 3, 4-dihydroxy-L-phenylalanine $\mathrm{C}_{9} \mathrm{H}_{11} \mathrm{NO}_{4}$ (Sigma, St. Louis, MO, USA), dimethyl sulfoxide analytical grade (Fisher Scientific, Loughborough, UK), kojic acid $\mathrm{C}_{6} \mathrm{H}_{6} \mathrm{O}_{4}$ (Sigma, St. Louis, MO, USA), tyrosinase (catechol oxidasemonophenol, dihydroxyphenylalanine) 3400 units/mg solid (Sigma, St. Louis, MO, USA).

\section{Extraction of samples}

Fresh fertile fronds were extracted at a ratio of $50 \mathrm{~mL}$ $70 \%$ methanol to $1 \mathrm{~g}$ of leaf material after liquid nitrogen-aided crushing. For the rhizomes, $1.0 \mathrm{~g}$ of de-skinned rhizome was extracted at a ratio of $50 \mathrm{~mL} 50 \%$ methanol to $1 \mathrm{~g}$ of rhizome. The methanol concentrations chosen for extraction were based on preliminary extraction efficiency screening, where 70 and $50 \%$ methanol were found to be more efficient at extracting the fertile fronds and rhizomes respectively. The extracts were then filtered with a Buchner funnel. The methanolic extracts were stored at $-20^{\circ} \mathrm{C}$ when not in use.

\section{Determination of antioxidant activity}

\section{Determination of total phenolic content (TPC)}

The determination of the total phenolic content of the samples was done using a procedure modified from Kähkönen et al. [17] utilizing the Folin-Ciocalteu reagent. Samples (300 $\mu \mathrm{L}$, in triplicate) were mixed with $1.5 \mathrm{~mL}$ of the $10 \%$ Folin-Ciocalteu reagent, followed by an addition of $1.2 \mathrm{~mL}$ of $7.5 \%(\mathrm{w} / \mathrm{v})$ sodium carbonate $\left(\mathrm{Na}_{2} \mathrm{CO}_{3}\right)$ solution. The test tubes were then left to stand for $30 \mathrm{~min}$ in the dark at room temperature before the absorbance values were measured at $765 \mathrm{~nm}$. The total phenolic content was expressed as mg gallic acid equivalent per $100 \mathrm{~g}$ of sample (mg GAE/100 g).

\section{Total flavonoid content (TFC)}

Flavonoid content in the extract was determined with the aluminium chloride colorimetric method as described in Chang et al. [18]. Equal volumes of $10 \%$ aluminium chloride and $1.0 \mathrm{M}$ potassium acetate $(0.1 \mathrm{~mL}$ each $)$ were 
added to $0.5 \mathrm{~mL}$ of extract, followed by $2.8 \mathrm{~mL}$ of distilled water. The solutions were mixed well and incubated at room temperature for $30 \mathrm{~min}$ before the absorbance was taken at $415 \mathrm{~nm}$. The flavonoid concentration was expressed as mg quercetin equivalent per $100 \mathrm{~g}$ sample, mg QE/100 g.

\section{DPPH radical scavenging assay (FRS)}

The DPPH. assay was based on the procedures described in Leong and Shui [19] and Miliauskas et al. [20] where the reduction of the DPPH (2,2-diphenyl-1-picrylhydrazyl) radical was measured spectrometrically to determine the radical scavenging activity of the extract. Two $\mathrm{mL}$ of DPPH. solution $(5.9 \mathrm{mg}$ in $100 \mathrm{~mL}$ methanol) was added to $1 \mathrm{~mL}$ of three different concentrations of the of sample extract (diluted with methanol). The absorbance of the solution was measured at $517 \mathrm{~nm}$ after a $30 \mathrm{~min}$ incubation time. The free radical scavenging activity (FRS) was expressed as ascorbic acid (AA) equivalent antioxidant capacity, in $\mathrm{mg} \mathrm{AA} / 100 \mathrm{~g}$ using the equation: $\mathrm{AEAC}=\mathrm{IC}_{50(\mathrm{AA})} / \mathrm{IC}_{50 \text { (sample) }} \times 10^{5} . \mathrm{IC}_{50}$ of $\mathrm{AA}$ used for calculation of FRS was $0.00387 \mathrm{mg} / \mathrm{mL}$.

\section{Ferric reducing power (FRP) assay}

The reducing power of the extracts was determined using potassium hexacyanoferrate(III) as described in the procedure described by Tan and Chan [21]. The FRP assay was used to assess the ability of any antioxidants present in the extracts to reduce ferric ions $\left(\mathrm{Fe}^{3+}\right)$ to ferrous ions $\left(\mathrm{Fe}^{2+}\right)$. One $\mathrm{mL}$ of sample extract of different concentration (diluted with methanol) was added with $2.5 \mathrm{~mL}$ of $0.2 \mathrm{M}$ phosphate buffer ( $\mathrm{pH}$ 6.7) and the same volume of $1 \%(\mathrm{w} / \mathrm{v})$ potassium ferricyanide. The solutions were mixed and incubated in $50{ }^{\circ} \mathrm{C}$ water bath for $20 \mathrm{~min}$. Subsequently, $2.5 \mathrm{~mL}$ of $10 \%$ trichloroacetic acid was added to stop the reaction. Then, the solution in each test tube was separated into aliquots of $2.5 \mathrm{~mL}$, added with $2.5 \mathrm{~mL}$ of Milli-Q water and $0.5 \mathrm{~mL}$ of $0.1 \% \mathrm{FeCl}_{3}$. The solutions were mixed and left on bench for 30 min before the absorbance was measured at $700 \mathrm{~nm}$. FRP was expressed as $\mathrm{mg}$ gallic acid equivalent per gram of sample, $\mathrm{mg}$ $\mathrm{GAE} / \mathrm{g}$.

\section{Ferrous ion chelating (FIC) assay}

The determination of ferrous ion chelating strength of the extract was based on the procedures described in Mau et al. [22], and Singh and Rajini [23]. One $\mathrm{mL}$ of $0.1 \mathrm{mM} \mathrm{FeSO}_{4}$ was added to $1 \mathrm{~mL}$ of sample of different concentrations $(0.2,0.5$ and $1 \mathrm{~mL}$ of extract, diluted with methanol), followed by $1 \mathrm{~mL}$ of $0.25 \mathrm{mM}$ ferrozine. The mixtures were incubated at room temperature for $10 \mathrm{~min}$ before the absorbance was measured at $562 \mathrm{~nm}$. It was expressed as the percentage of iron chelating activity. EDTA $(0.017-0.067 \mathrm{mg} / \mathrm{mL})$ was used as a positive control.

\section{Lipid peroxidation inhibition (LPI)}

Lipid peroxidation inhibition was adapted from Kumazawa et al. [24] based on the bleaching of $\beta$-carotene with slight modifications. Six mg of $\beta$-carotene was dissolved in $50 \mathrm{~mL}$ of chloroform, and $4 \mathrm{~mL}$ of the solution was mixed with $40 \mathrm{mg}$ of linoleic acid and $400 \mathrm{mg}$ of Tween 40 emulsifier in a conical flask. Nitrogen gas was then used to evaporate the chloroform. Then, $100 \mathrm{~mL}$ of oxygenated Milli-Q water was added and the flask was shaken for the mixture to be fully dissolved. Immediately after water was added, the absorbance of the mixture was measured at 470 and $700 \mathrm{~nm}$ using Perkin-Elmer doublebeam spectrophotometer. Next, $3 \mathrm{~mL}$ of the emulsion was added into test tubes with different volume of sample (10, 50 and $100 \mu \mathrm{L})$. The tubes were sealed with parafilm and incubated at $50{ }^{\circ} \mathrm{C}$ water bath for an hour before the absorbance was measured again. For control, $100 \mu \mathrm{L}$ of methanol was used instead of the sample. The blank was prepared by adding the same volume of sample with the emulsion of $400 \mathrm{mg}$ Tween 40 emulsifier and $100 \mathrm{~mL}$ of water but without linoleic acid and $\beta$-carotene solution. The absorbance (A) at $700 \mathrm{~nm}$ was taken in order to correct the haze present in the solution. The LPI was calculated using the formula:

Degradation Rate $(\mathrm{DR})=\left[\operatorname{Ln}\left(\mathrm{A}_{\text {Initial }} / \mathrm{A}_{\text {Sample }}\right)\right] / 60$

$$
\begin{aligned}
& \text { Antioxidant Activity }(\% \mathrm{AOA}) \\
& \quad=\left[1-\left(\mathrm{DR}_{\text {Sample }} / \mathrm{DR}_{\text {Control }}\right)\right] \times 100 .
\end{aligned}
$$

\section{Determination of tyrosinase inhibition activity}

The measurement of tyrosinase inhibition activity of extracts was based on the method used by Masuda et al. [25], with slight modification. The method utilizes L-DOPA and a 96-well microplate for screening of multiple samples simultaneously. For testing of the sample extract, the wells in triplicate were added with $80 \mu \mathrm{L}$ of buffer (0.1 M phosphate buffer, $\mathrm{pH} 6.8), 40 \mu \mathrm{L}$ of tyrosinase $(1 \mathrm{mg} / \mathrm{mL}$ of tyrosinase diluted 50 -folds with Milli$\mathrm{Q}$ water), and $40 \mu \mathrm{L}$ of sample $(1 \mathrm{mg}$ of freeze-dried extract in $400 \mu \mathrm{L}$ of $50 \%$ DMSO), and lastly $40 \mu \mathrm{L}$ of L-DOPA. For the control, the same reagents were added to the wells except that the sample was substituted with $40 \mu \mathrm{L}$ of DMSO. The blank contained $120 \mu \mathrm{L}$ of buffer, $40 \mu \mathrm{L}$ of tyrosinase, and $40 \mu \mathrm{L}$ of sample. The mixture in each well was mixed and left on the bench for $30 \mathrm{~min}$ (after the addition of L-DOPA). Subsequently, the microplate was measured using BIOTEK PowerWave XS Microplate Scanning Spectrophotometer at the absorbance of $475 \mathrm{~nm}$, with reference wavelength at $700 \mathrm{~nm}$. 
The percentage tyrosinase inhibition activity was calculated using equation below:

$$
\begin{aligned}
& \text { \% Tyrosinase inhibition activity } \\
& \quad=\left[1-\left(\mathrm{A}_{\text {Sample }} / \mathrm{A}_{\text {Control }}\right)\right] \times 100 .
\end{aligned}
$$

\section{Statistical analysis}

Statistical analysis was carried out with one-way ANOVA and the Tukey HSD test was used to identify any significance between the TPC values of the samples. $p<0.05$ was considered to be significantly different.

\section{Results and discussion}

The TPC, FRS, FRP and TFC results reported in Table 1 are a measure of the primary antioxidant activity-the ability to scavenge free radicals, thus inhibiting chain initiation and terminating chain propagation [26]. D. quercifolia fertile fronds exhibited a very high TPC of $2939 \pm 469 \mathrm{mg}$ GAE/100 g-consistent with previous findings reported by our research group where $D$. quercifolia fertile fronds ranked second highest in TPC amongst the fifteen ferns screened with an average TPC exceeding $2500 \mathrm{mg}$ GAE/100 g [27]. D. quercifolia had the highest TPC of the three species screened: approximately three times higher than the fronds of $D$. rigidula and nearly ten-fold higher than the fronds of $D$. sparsisora; a surprising result given the similar physical appearance of the D. quercifolia and D. sparsisora fronds. The results for the FRS activity $\left(\mathrm{IC}_{50}\right.$ and $\left.\mathrm{AEAC}\right)$ reflected a similar correlation, with $D$. quercifolia fronds exhibiting the highest activity, followed by $D$. rigidula and $D$. sparsisora. However, despite the higher TPC and FRS in $D$. rigidula fronds compared to $D$. sparsisora fronds, the FRP between the fronds of both species were similar thus indicating that phenolic compounds may not necessarily be the only reducing agents present in the fronds of $D$. sparsisora.

When compared to the fertile fronds, the rhizomes of $D$. quercifolia and D. rigidula exhibited lower primary antioxidant activity, with lower TPC and weaker FRP activity (Table 1 ). Only in $D$. sparsisora was there no significant difference in TPC and FRP between the leaves and rhizomes, but the rhizomes showed significantly higher FRS than the fronds. Despite the TPC of D. sparsisora's leaves and rhizomes being comparable with one another, the free-radical scavenging capability of the rhizomes was considerably higher than would be expected based on the TPC alone. This indicates the rhizomes of D. sparsisora either contain non-phenolic free-radical scavengers, or the phenols in the rhizomes are better free radical scavengers than those in the fertile fronds. While it has been reported that the leaves of a plant may contain more phenols than the rhizomes [28, 29], this is nevertheless an interesting finding as thus far, only the rhizomes of these ferns have been used in ethnobotany.

The lipid peroxidation inhibition (LPI) activity (Fig. 1), measures the ability of an antioxidant to inhibit lipid peroxidation, thus being a more accurate assessment of the hydrophobic antioxidants present. This is in contrast to the FRS activity (Table 1) that measures the antioxidant activity of both hydrophilic and hydrophobic compounds. All three species showed considerable antioxidant activity of $50 \%$ or above at the maximum concentration tested (645.2 $\mu \mathrm{g}$ fresh sample $/ \mathrm{mL}$ ) in a concentration-dependant manner. The LPI between the fronds and rhizomes were comparable despite the differences in other facets of their antioxidant activity (Table 1), indicating the hydrophobic antioxidants present in both the fronds and rhizomes were comparable in antioxidant activity. Examples of such hydrophobic antioxidants would include terpenoids/carotenoids and tocopherols [30].

While the TPC, FRS, FRP, TFC and BCB assays are measures of primary antioxidant activity, ferrous ion chelating (FIC) activity is a measure of secondary antioxidant activity-the ability to prevent the formation of radicals, such as those generated by the Fenton reaction in the presence of free ferrous ions [31]. Interestingly, the fertile fronds and rhizomes of all three species showed a

Table 1 Total phenolic content (TPC), free radical scavenging activity (IC50 and ascorbic acid equivalent antioxidant

\begin{tabular}{|c|c|c|c|c|c|c|}
\hline Species & Part & TPC (mg GAE/100 g) & $I C_{50}(\mathrm{mg} / \mathrm{mL})$ & AEAC (mg AA/100 g) & $\mathrm{FRP}(\mathrm{mg} \mathrm{GAE} / \mathrm{g})$ & TFC (mg QE/100 g) \\
\hline \multirow[t]{2}{*}{ D. quercifolia } & Frond & $2939 \pm 469^{a}$ & $0.09 \pm 0.01^{\mathrm{a}}$ & $4456 \pm 571^{a}$ & $17.5 \pm 2.2^{\mathrm{a}}$ & $0.1 \pm 0.0^{\mathrm{a}}$ \\
\hline & Rhizome & $1732 \pm 437^{b}$ & $0.17 \pm 0.03^{b}$ & $2273 \pm 415^{b}$ & $9.5 \pm 1.3^{b}$ & $5.0 \pm 0.1^{b}$ \\
\hline \multirow[t]{2}{*}{ D. rigidula } & Frond & $1031 \pm 132^{c}$ & $0.79 \pm 0.22^{c}$ & $507.3 \pm 151.0^{c}$ & $2.3 \pm 0.3^{c}$ & $4.7 \pm 0.9^{b}$ \\
\hline & Rhizome & $305.5 \pm 17.2^{d}$ & $1.02 \pm 0.16^{c}$ & $380.6 \pm 64.9^{c}$ & $1.0 \pm 0.2^{d}$ & $3.1 \pm 0.1^{c}$ \\
\hline \multirow[t]{2}{*}{ D. sparsisora } & Frond & $316.6 \pm 19.5^{d}$ & $2.01 \pm 0.62^{d}$ & $199.9 \pm 53.2^{d}$ & $2.1 \pm 0.3^{c}$ & $1.0 \pm 0.5^{d}$ \\
\hline & Rhizome & $367.2 \pm 20.9^{d}$ & $0.81 \pm 0.18^{c}$ & $489.4 \pm 126.5^{c}$ & $2.2 \pm 0.6^{c}$ & $0.1 \pm 0.1^{\mathrm{a}}$ \\
\hline
\end{tabular}
capacity, AEAC), ferric reducing power (FRP) and total flavonoid content (TFC) of Drynaria sp fertile fronds and rhizomes

Results are expressed as mean $\pm S D(n=3)$. For each column, values followed by the same letter are not significantly different at $p<0.05$ as measured by the Tukey HSD test 


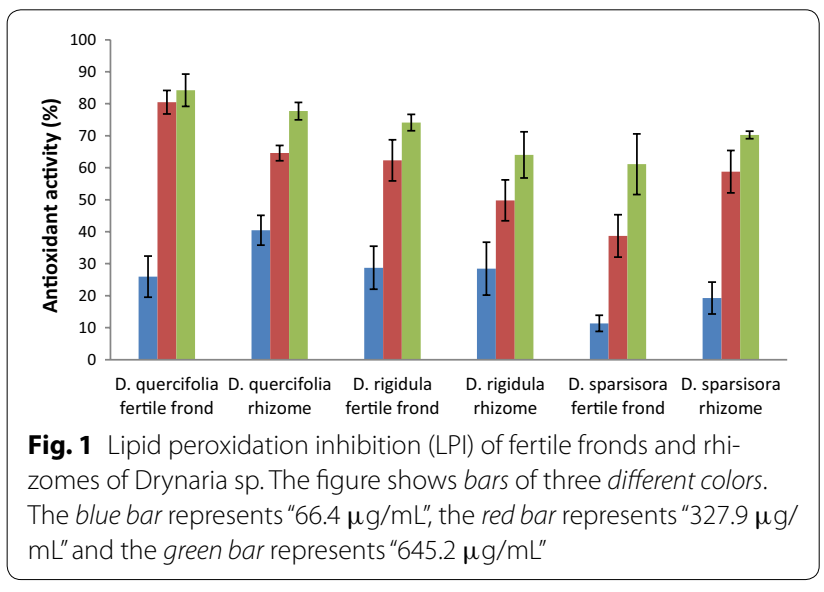

low ferrous ion chelating activity, with the fertile fronds of $D$. rigidula showing the highest chelating activity at approximately $45 \%$ at $7 \mathrm{mg} / \mathrm{mL}$ (Fig. 2). This appears to be a common phenomena amongst ferns, as even those with exceptionally high TPC values exceeding $2500 \mathrm{mg}$ GAE/100 g, such as Cyathea latebrosa, Cibotium barometz and Dicranopteris linearis, have been reported to exhibit poor chelating activity [27]. The phenolic compounds present in the Drynaria samples are likely weak iron chelators, and thus, weak secondary antioxidants.

As shown in Table 2, D. quercifolia fronds showed a high tyrosinase inhibition activity (exceeding $50 \%$ ) [32], and may therefore have possible commercial applications as a natural tyrosinase inhibitor, such as in the cosmetics industry (skin whitening) and food industry (antibrowning preservation) [5]. Interestingly however, most of the extracts exhibited tyrosinase enhancement activity, effectively acting as tanning agents. While reports on tyrosinase inhibition are more common, a number of

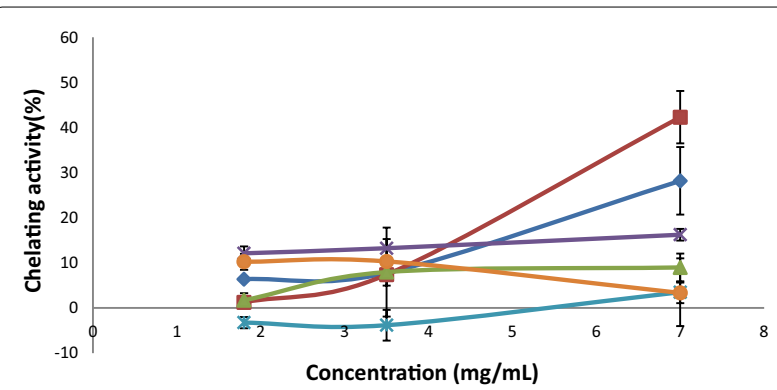

Fig. 2 Ferrous iron chelating (FIC) activity in fertile fronds and rhizomes of Drynaria sp. The figure shows six lines with different colors. The darker blue line represents "Drynaria quercifolia fertile fronds". The red line represents "Drynaria rigidula fertile fronds". The green line represents "Drynaria sparsisora fertile fronds". The purple line represents "Drynaria quercifolia rhizome". The lighter blue line represents "Drynaria rigidula rhizome". The orange line represents "Drynaria sparsisora rhizome"
Table 2 Tyrosinase inhibition (\%) of Drynaria sp fertile fronds and rhizomes $(0.5 \mathrm{mg} / \mathrm{mL})$

\begin{tabular}{llc}
\hline Species & Part & Tyrosinase inhibition (\%) \\
\hline D. quercifolia & Frond & $56.6 \pm 5.0$ \\
& Rhizome & $-27.9 \pm 11.1$ \\
D. rigidula & Frond & $24.9 \pm 5.4$ \\
& Rhizome & $-65.0 \pm 6.9$ \\
D. sparsisora & Frond & $-153.7 \pm 10.1$ \\
& Rhizome & $-33.7 \pm 2.4$ \\
\hline
\end{tabular}

Data in mean $\pm S D(n=3)$. Negative values imply tyrosinase enhancement activity

extracts are known to increase melanogenesis, including kava rhizomes, lotus flowers and mangosteen leaves [33]. Although phenolic compounds are often tyrosinase inhibitors, several are capable of acting as tyrosinase activity enhancers, such as naringenin [5] and 4'-O- $\beta$-Dglucopyranosyl-( $1 \rightarrow 2)-\beta$-D-glucopyranosyl-quercetin3-O- $\beta$-D-glucopyranosyl-( $1 \rightarrow 4)$ - $\beta$-D-glucopyranoside [34]. Macrocycles such as cryptand and crown ethers are also capable of enhancing tyrosinase activity by acting as carriers for water molecules, which in turn increases the enzyme's activity [35]. Tyrosinase enhancement can see application in skin care products designed to reduce UV damage for skin cancer prevention [34], and as a treatment for hypopigmentation [33]. It can also prove useful in the cosmetics industry, for self-tanning [33]. The exact causal agent for this tyrosinase enhancement would require further investigation, particularly in the fronds of $D$. sparsisora, which showed remarkable tyrosinase enhancement activity.

\section{Conclusion}

Of the three fern species screened, $D$. quercifolia fertile fronds exhibited the highest TPC, FRS, FRP and LPI. The fertile fronds of $D$. quercifolia and $D$. rigidula showed significantly higher TPC and FRP when compared to their rhizomes, with $D$. quercifolia fronds also exhibiting significantly higher FRS. D. sparsisora rhizomes on the other hand showed similar antioxidant activity with the fronds, with the exception of the rhizome's FRS being significantly higher than that of the fronds. Interestingly, regardless of the differences in other antioxidant properties, the LPI between the fronds and rhizomes of all three species were comparable at the highest concentration studied. The fronds of $D$. quercifolia showed good tyrosinase inhibition, while the fronds of $D$. sparsisora showed remarkable tyrosinase enhancement. These findings may hopefully provide further impetus into looking at the fronds of other ferns which are commonly used mostly for their rhizomes. 


\section{Authors' contributions}

JTBL carried out all the laboratory bench work; collected and analyzed the data; and wrote this paper. LYY conceptualized the project design and provided advice and guidance throughout the project and writing of this paper. Both authors read and approved the final manuscript.

\section{Acknowledgements}

The authors wish to thank Monash University Malaysia for the financial support.

\section{Compliance with ethical guidelines}

\section{Competing interests}

The authors declare that they have no competing interests.

Received: 12 February 2014 Accepted: 7 September 2015 Published online: 22 September 2015

\section{References}

1. Lee JH, Park KH, Lee M, Kim H, Seo WD, Kim JY, Baek I, Jang DS, Ha TJ. Identification, characterisation, and quantification of phenolic compounds in the antioxidant activity-containing fraction from the seeds of Korean perilla (Perilla frutescens) cultivars. Food Chem. 2013;136(2):843-52.

2. Staszewski MV, Pilosof AMR, Jagus RJ. Antioxidant and antimicrobial performance of different argentinean green tea varieties as affected by whey proteins. Food Chem. 2011;125:186-92.

3. Bansal S, Choudhary S, Sharma M, Kumar SS, Lohan S, Bhardwaj V, Syan $\mathrm{N}$, Jyoti S. Tea: a native source of antimicrobial agents. Food Res Int. 2013;53(2):568-84.

4. Cai Y, Luo Q, Sun M, Corke H. Antioxidant activity and phenolic compounds of 112 traditional Chinese medicinal plants associated with anticancer. Life Sci. 2004;74:2157-84

5. Chang T. An updated review of tyrosinase inhibitors. Int J Mol Sci. 2009;10(6):2440-75.

6. Higashi Y, Asanuma M, Miyazaki I, Ogawa N. Inhibition of tyrosinase reduces cell viability in catecholaminergic neuronal cells. J Neurochem. 2002; 75(4):1771-4.

7. Grimm J, Mueller A, Hefti F, Rosenthal A. Molecular basis for catecholaminergic neuron diversity. Proc Natl Acad Sci USA. 2004;101(38):13891-6.

8. Mithraja MJ, Irudayaraj V, Kiruba S, Jeeva S. Antibacterial efficacy of Drynaria quercifolia (L.) J. Smith (Polypodiaceae) against clinically isolated urinary tract pathogens. Asia-Pa. J Trop Biomed. 2012;2:S131-5.

9. Chang HC, Agrawal DC, Kuo CL, Wen JL, Chen CC, Tsay HS. In vitro culture of Drynaria fortunei, a fern species source of Chinese medicine "Gu-SuiBu". Vitro Cell Dev Biol Plant. 2007;43:133-9.

10. Khan A, Haque E, Rahman MM, Mosaddik A, Rahman M, Sultana N. Isolation of antimicrobial constituent from rhizome of Drynaria quercifolia and its sub-acute toxicological studies. DARU. 2007;15(4):205-11.

11. Ramesh N, Viswanathan MB, Saraswathy A, Balakrishna K, Brindha P, Lakshmanaperumalsamy P. Phytochemical and antimicrobial studies on Drynaria quercifolia. Fitoterapia. 2001;72:934-6.

12. Sen A, Ghosh PD. A note on the ethnobotanical studies of some pteridophytes in Assam. Indian J Tradit Knowl. 2011;10:292-5.

13. Johnson T. CRC Ethnobotany Desk Reference. San Francisco: California CRC Press; 1999

14. Yang F, Zhang C, Wu G, Liang S, Zhang X. Endangered Pteridophytes and their distribution in Hainan Island, China. Am Fern J. 2011:101(2):105-16.

15. Wee YC. A Guide to the Ferns of Singapore. 3rd ed. Singapore: Singapore Science Centre; 2002

16. Ranil RHG, Pushpakumara DKNG. Occurrence of Drynaria sparsisora (Desv.) T. Moore, in the lower Hantana area, Sri Lanka. J Natl Sci Found Sri Lanka. 2008;36(4):331-4.

17. Kähkönen MP, Hopia Al, Vuorela HJ, Rauha JP, Pihlaja K, Kujala TS, Heihonen M. Antioxidant activity of plant extracts containing phenolic compounds. J Agric Food Chem. 1999;47(10):3954-62.
18. Chang C, Yang M, Wen $\mathrm{H}$, Chern J. Estimation of total flavonoid content in propolis by two complementary colorimetric methods. J Food Drug Anal. 2002;10(3):178-82.

19. Leong L, Shui G. An investigation of antioxidant capacity of fruits in Singapore markets. Food Chem. 2002;76(1):69-75.

20. Miliauskas $G$, Venskutonis PR, van Beek TA. Screening of radical scavenging activity of some medicinal and aromatic plant extracts. Food Chem. 2004;85(2):231-7.

21. Tan YP, Chan EWC. Antioxidant, antityrosinase and antibacterial properties of fresh and processed leaves of Anacardium occidentale and Piper betle. Food Biosci. 2014;6:17-23.

22. Mau JL, Lai EYC, Wang NP, Chen CC, Chang CH, Chyau CC. Composition and antioxidant activity of the essential oil from Curcuma zedoaria. Food Chem. 2003;82(4):583-91.

23. Singh N, Rajini PS. Free radical scavenging activity of an aqueous extract of potato peel. Food Chem. 2004;85:611-6.

24. Kumazawa S, Taniguchi M, Suzuki Y, Shimura M, Kwon MS, Nakayama T. Antioxidant activity of polyphenols in carob pods. J Agric Food Chem. 2002;50:373-7.

25. Masuda T, Yamashita D, Takeda Y, Yonemori S. Screening for tyrosinase inhibitors among extracts of seashore plants and identification of potent inhibitors from Garcinia subelliptica. Biosci Biotech Biochem. 2005;69(1):197-201

26. Lim YY, Quah EPL. Antioxidant properties of Phyllanthus amarus extracts as affected by different methods. Food Chem. 2007;103:734-40.

27. Lai HY, Lim YY. Evaluation of antioxidant activities of the methanolic extracts of selected ferns in Malaysia. Int J Environ Sci Dev. 2011;2:442-7.

28. Chan EWC, Lim YY, Omar M. Antioxidant and antibacterial activity of leaves of Etlingera species (Zingiberaceae) in Peninsular Malaysia. Food Chem. 2007;104:1586-93

29. Elzaawely AA, Xuan TD, Tawata S. Essential oils, kava pyrones and phenolic compounds from leaves and rhizomes of Alpinia zerumbet (Pers.) B.L. Burtt. \& R.M. Sm. and their antioxidant activity. Food Chem. 2006;103(2):486-94.

30. Graßmann J. Terpenoids as plant antioxidants. Vitam Horm. 2005;72:505-35.

31. Chandrasekara A, Shahidi F. Bioaccessibility and antioxidant potential of millet grain phenolics as affected by simulated in vitro digestion and microbial fermentation. J Funct Foods. 2012;4(1):226-37.

32. Baurin N, Arnoult E, Scior T, Do QT, Bernard P. Preliminary screening of some tropical plants for anti-tyrosinase activity. J Ethnopharmacol. 2002;82:155-8.

33. Hamid MA, Sarmidi MR, Park CS. Mangosteen leaf extract increases melanogenesis in B16F1 melanoma cells by stimulating tyrosinase activity in vitro and by up-regulating tyrosinase gene expression. Int J Mol Med. 2012;29(2):209-17.

34. Yamauchi K, Mitsunaga T, Batubara I. Novel quercetin glucosides from Helminthostachys zeylanica root and acceleratory activity of melanin biosynthesis. J Nat Med. 2013;67(2):369-74.

35. Broos J, Arends R, van Dijk GB, Verboom W, Engbersen JFJ, Reinhoudt DN Enhancement of tyrosinase activity by macrocycles in the oxidation of p-cresol in organic solvents. J Chem Soc Perk T. 1996;1:1415-7.

\section{Submit your next manuscript to BioMed Central and take full advantage of:}

- Convenient online submission

- Thorough peer review

- No space constraints or color figure charges

- Immediate publication on acceptance

- Inclusion in PubMed, CAS, Scopus and Google Scholar

- Research which is freely available for redistribution

Submit your manuscript at www.biomedcentral.com/submit
( Biomed Central 